\title{
Rapid Regeneration of Dracocephalum Kotschyi Boiss. from Nodal Explants
}

\author{
Otroshy Mahmoud*, Moradi Kosar \\ Department of Tissue culture, Branch of Central Region of Iran, Agricultural Biotechnology Research Institute of Iran (ABRII), \\ P.O. Box 85135-487, Isfahan, Iran \\ *otroshy@yahoo.com
}

\begin{abstract}
The Dracocephalum Kotschyi L., a wild-growing flowering plant belonging to the family Lamiaceae is best known for the essential oils common to many members of the family. The present study showed the procedure for propagation of $D$. kotschyi using nodal segments from in vitro germinated plants. A high frequency and rapid regeneration protocol was growing and developing from nodal explants of $D$. kotschyi on the medium MS containing $2 \mathrm{mg} / \mathrm{L}$ BAP plus $0.5 \mathrm{mg} / \mathrm{L}$ NAA. Histochemical analysis showed a direct induction of more teratological protuberances that arise around the cut end of the explants. After hardening, the rooted plants were transferred to the greenhouse condition where they normally grew, matured and flowered with a survival rate of $90-95 \%$. We concluded that the present protocol can be efficiently used for mass propagation of $D$. kotschyi.
\end{abstract}

Keywords- Dracocephalum Kotschyi; Explant; Medicinal; Lamiaceae

\author{
Abbreviations - \\ BAP: 6-benzylaminopurine; \\ IBA: indole-3-butyric acid; \\ KIN: kinetin; NAA: $\alpha$-naphthalene acetic acid; \\ AC: activated charcoal
}

\section{INTRODUCTION}

Many species of lamiaceae are aromatic and often used as herbs, spices, folk medicines, and a source of fragrance. Dracocephalum kotschyi Boiss, is a wild-growing flowering plant, belonging to the family Lamiaceae which is knowing for the essential oils, common to other members in the family (Golshani et al., 2004). Many biologically active essential oils have been isolated from various members of the family in southwestern Asia. D. kotschyi has been used as a medicinal herb for several years in Iran folk medicine for its antispasmodic and analgesic properties (Jahaniani et al., 2005). Anti-hyperlipidemic (Sajjadi et al., 1998) and immunomodulatory (Amirghofran et al., 2000) effects have been reported for D. kotschyi. It was used by traditional medicine as a plant concoction for the treatment of many forms of cancer in humans. These traditional medicines believed that the concoction was specifically effective against leukemia and GI tract malignancy. Spinal-Z is an extract that is composed of two plants: Peganum harmala L. (Zygophyllaceae) seeds and D. kotschyi leaves (Sobhani et al., 2002; Jahaniani et al., 2005).

The preferentially inhibit multiplication of tumor cells may offer means of developing drugs effective against cancer in human. One of the methods for finding such agents is division plant material, particularly those which have been reported to have anti-cancer, anti-inflammatory, anti-fungal or anti-bacterial effects (Cordell et al., 1991; Cox and Balick, 1994; Wu et al., 2002). Spinal-Z is a traditional Iranian anticancer remedy (Sobhani et al., 2002; Jahaniani et al., 2005). The natural propagation of D. kotschyi by seed distribution is restricted mainly because of the sever seed dormancy. This, besides incorrect usage of the plant per people and presence of suboptimal natural conditions makes it to have been considered as a rare plant. In vitro micropropagation is an effective mean for quick multiplication of species in which it is necessary to obtain high result uniformity. In recent years, the interests in using these techniques for rapid and large-scale propagation of medicinal and aromatic plants have been significantly increased (Sahoo et al., 1997).

There are many in vitro studies have having been conducted on Lamiaceae species using different explants, like nodal segments, leaf explants and axillary buds (Begum et al., 2002; Nirmal and Sehgal, 2010; Winthrop and Simon, 2000). The present study is the first report showed the procedure for the micropropagation of $\mathrm{D}$. kotschyi using nodal cutting prepared from in vitro plants germinated.

\section{MATERIALS AND METHODS}

The experiment was carried out at the Tissue Culture Lab of the Agricultural Biotechnology Research Institute Central region of Iran in 2010. Seeds of Dracocephalum kotschyi, native cultivars were obtained from the Collection of Agricultural Research Center.

\section{A. Multiplication Of In Vitro Plantlets}

The seeds were washed with tap water for 5 - 10 minutes to remove surface contamination and then sterilized by immersing in $70 \%$ ethanol for 1 minute with vigorous shaking followed by 20 minutes in $15 \%$ sodium hypochlorite containing one drop of Tween 20 . The seeds were then rinsed three times with sterile distilled water in a laminar flow cabinet to remove minor amounts of disinfection liquid. For germinating, the seeds were cultured in a mug on $50 \mathrm{ml}$ of standard (Murashige and Skoog, 1962) containing $3 \%(\mathrm{~m} / \mathrm{v})$ sucrose and $0.6 \%(\mathrm{~m} / \mathrm{v})$ agar. Cultures were incubated in a growth chamber at temperature of $24^{\circ} \mathrm{C}$, a $16 \mathrm{~h}$ photoperiod provided and with a light intensity of 2000 lux provided by white fluorescent lamps. After four weeks, the germinated seeds had produced young seedlings 
with 5-9 leaves. Nodal segments (with one node) derived from these aseptic seedlings were used as explants.

\section{B. In Vitro Treatment with Plant Growth Regulators}

Nodal segments (0.5 - $1 \mathrm{~cm}$ length) were cultured on MS medium supplemented with (6-benzylaminopurine) or KIN (kinetin) with three concentrations $(0,1.0,2.0 \mathrm{mg} / \mathrm{l})$ combined with IBA (Indole-3-butyric acid) or NAA ( $\alpha$ naphthalene acetic acid). Three concentrations ( $0,0.2,0.5$ $\mathrm{mg} / \mathrm{l}$ ) of IBA or NAA were applied to enhance shoot formation. Sterilization was performed by autoclaving at $121^{\circ} \mathrm{C}$ for $20 \mathrm{~min}$. $\mathrm{pH}$ was adjusted at 5.8 before adding $0.6 \%(\mathrm{w} / \mathrm{v})$ agar and $0.4 \%(\mathrm{w} / \mathrm{v})$ activated charcoal. Five explants were aseptically cultured in a mug containing $50 \mathrm{ml}$ of the induction medium. The mugs were covered and sealed with household plastic foil for a period of 5 weeks and then transferred to the same conditions as mentioned above.

\section{Histological Studies}

The histological staining was carried out to establish the ontogeny of explants containing shoot buds. Explants at different stages of their development were fixed in FAA (formalin, acetic acid, absolute alcohol: 10, 5, 85; v/v) for 24 hours. After dehydrating in ethanol (70, 95 and 100\%) and xylene, textures were fixed in paraffin, sectioned with a microtome at $30 \mu \mathrm{m}$ and then stained with metylen blue. The sections were prepared in a lam for observation under a light microscope.

\section{Hardening and Acclimatization}

In general, 4 weeks-old rooted plantlets were acclimatized and out-planted in pots contained sterilized peat mass and vermiculite (3:1 ratio). The pots were covered with clear beaker having a few holes on it and were frequently watered to keep high humidity in a phytotron during 10 days. Hardened plantlets were out-planted in a greenhouse set at a day temperature $21^{\circ} \mathrm{C}$, a night temperature $19^{\circ} \mathrm{C}$, relative humidity $85 \%$ and a day length of $12 \mathrm{~h}$. Immediately after planting, the plantlets were irrigated and adequate soil moisture was maintained through daily watering. The proliferated plants showed 70-90\% survival rate during hardening and acclimatization.

\section{E. Data Collection}

Five weeks after transplanting, growth parameters including the number of shoots per explants, shoots length (cm) per explants and and the percentage of rooting of explants were recorded and the effect of different shoot induction media was evaluated.

\section{F. Experimental Design and Statistical Analysis}

The experiment was carried out in a completely randomized factorial design. Data were statistically analyzed using the SAS software (Version 8). When the ANOVA indicated significant treatment effects (5 or 1\%) based on the F-test, the Duncan's Multiple Range Test $(\mathrm{P} \leq 0.05)$ was used as a method to determine which treatments were statistically different from other treatments.

\section{RESULTS}

In a preliminary experiment, nodal explants from grown plants of Dracocephalum kotschyi were inoculated on MS supplemented with growth regulations BAP and Kin alone or in combination at different concentrations $(0,1.0,2.0$ $\mathrm{mg} / \mathrm{L})$ plus three concentrations $(0,0.2,0.5 \mathrm{mg} / \mathrm{L})$ of IBA or NAA, for production of multiple shoots (Fig. 1).

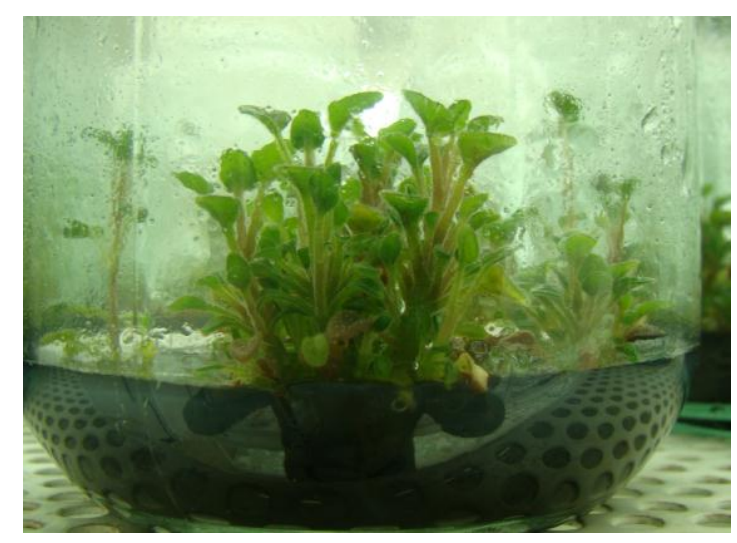

Fig. 1 Nodal segments of Dracocephalum kotschyi Boiss taken from aseptic seedlings as explants on medium containing activated charcoal in combination with growth regulators

The multiplication efficiency of nodal segments from plants was significant when estimated four to five weeks. Different concentrations and combinations of growth regulators showed significantly different responses in terms of number of shoots per explants, shoots length $(\mathrm{cm})$ per explants and the percentage of rooting of explants (Table 1).

TABLE I EFFECT OF GROWTH REGULATORS BAP, KIN, IBA AND NAA ON THE NUMBER OF SHOOTS PER EXPLANTS, SHOOTS LENGTH (CM) PER EXPLANTS AND AND THE PERCENTAGE OF ROOTING OF EXPLANTS OF RESPONSE ON SHOOTS INDUCTION FROM NODAL AND EXPLANTS OF DRACOCEPHALUM KOTSCHYI BOISS. (LAMIACEAE)

\begin{tabular}{|c|c|c|c|c|c|c|}
\hline & $\begin{array}{c}\text { Growth } \\
\text { regulators } \\
\text { (mg/L) }\end{array}$ & $\begin{array}{c}\text { Number of } \\
\text { shoots/ } \\
\text { explant }\end{array}$ & $\begin{array}{c}\text { Shoots length/ } \\
\text { explants (cm) }\end{array}$ & $\begin{array}{c}\text { Rooting } \\
(\%)\end{array}$ \\
\hline BAP & KIN & NAA & IBA & & & $6.00 \mathrm{~b}$ \\
\hline 1 & - & 0.2 & - & $5.10 \mathrm{~b}$ & $68.4 \mathrm{~b}$ \\
\hline 2 & - & 0.5 & - & $7.11 \mathrm{a}$ & $8.5 \mathrm{a}$ & $90.08 \mathrm{a}$ \\
\hline 1 & - & - & 0.2 & $3.73 \mathrm{~d}$ & $5.00 \mathrm{c}$ & $48.2 \mathrm{c}$ \\
\hline 2 & - & - & 0.5 & $5.18 \mathrm{~b}$ & $5.60 \mathrm{c}$ & $50.08 \mathrm{c}$ \\
\hline- & 1 & 0.2 & - & $2.00 \mathrm{~b}$ & $4.2 \mathrm{c}$ & $15.23 \mathrm{~d}$ \\
\hline- & 2 & 0.5 & - & $2.13 \mathrm{~b}$ & $5.0 \mathrm{~b}$ & $18.12 \mathrm{~b}$ \\
\hline- & 1 & - & 0.2 & $2.00 \mathrm{~b}$ & $4.2 \mathrm{c}$ & $15.23 \mathrm{~d}$ \\
\hline- & 2 & - & 0.5 & $2.13 \mathrm{~b}$ & $5.0 \mathrm{~b}$ & $18.12 \mathrm{~b}$ \\
\hline- & - & 0.2 & - & $0.80 \mathrm{e}$ & $3.5 \mathrm{~d}$ & $10.20 \mathrm{e}$ \\
\hline- & - & 0.5 & - & $1.71 \mathrm{e}$ & $2.31 \mathrm{~d}$ & $20.9 \mathrm{~d}$ \\
\hline- & - & - & 0.2 & $3.5 \mathrm{~d}$ & $0.40 \mathrm{~d}$ & $15.2 \mathrm{~d}$ \\
\hline- & - & - & 0.5 & $2.00 \mathrm{ab}$ & $1.02 \mathrm{e}$ & $19.3 \mathrm{~d}$ \\
\hline 1 & - & - & - & $3.50 \mathrm{~d}$ & $4.08 \mathrm{~d}$ & $38.2 \mathrm{~d}$ \\
\hline 2 & - & - & - & $4.53 \mathrm{c}$ & $4.66 \mathrm{~d}$ & $39.00 \mathrm{~d}$ \\
\hline- & 1 & - & - & $0.50 \mathrm{e}$ & $3.08 \mathrm{~d}$ & $10.2 \mathrm{e}$ \\
\hline- & 2 & - & - & $1.53 \mathrm{e}$ & $4.66 \mathrm{c}$ & $16.00 \mathrm{c}$ \\
\hline control & - & - & - & $0.27 \mathrm{e}$ & $3.00 \mathrm{e}$ & $18.43 \mathrm{e}$ \\
\hline
\end{tabular}
A.

The best treatment are shown with the values with Letter

After 4 weeks of culture, as a supplement $2.0 \mathrm{mg} / \mathrm{L} \mathrm{BAP}$ plus $0.5 \mathrm{mg} / \mathrm{L}$ NAA resulted in maximum proliferation was noted in $90 \%$ cultured explants (Fig. 2 and Table 1). 


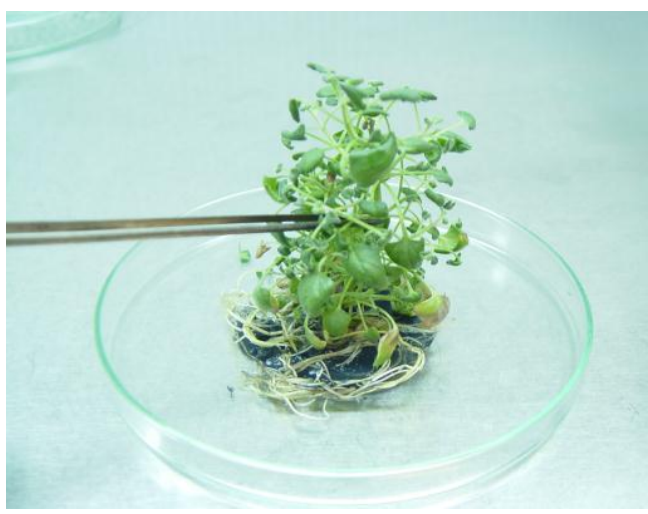

Fig. 2 Seedling of Dracocephalum kotschyi Boiss with expanded buds and extended roots after 4 weeks of regenerating in medium containing activated charcoal plus plant growth regulators

Media containing KIN alone or in combinations with other growth regulators auxin had the least effectiveness in inducing regeneration (Table 1). The maximum number of roots per explant was obtained in MS combined with BAP (2 $\mathrm{mg} / \mathrm{L}$ ) plus $0.5 \mathrm{mg} / \mathrm{L}$ NAA (Table 1). The some percentage of explants that hadn't rooting on regeneration medium after that transportation to rooting medium includes $0.2 \mathrm{mg} / \mathrm{L}$ NAA was the safe that treatment approximately all explants properly rooted (Fig. 3).

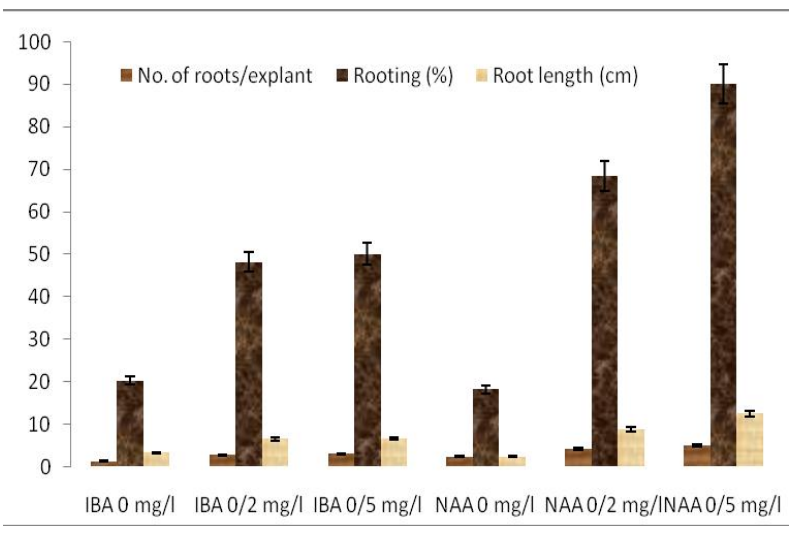

Fig. 3 Effects of different concentration growth regulators on the Number of roots, per explants, root length $(\mathrm{cm})$ and the percentage of rooting of explants.

Histochemical staining of the regenerated shoot buds explants also showed initial meristems and primordial formation in regions of bud formation culturing (Fig. 4).

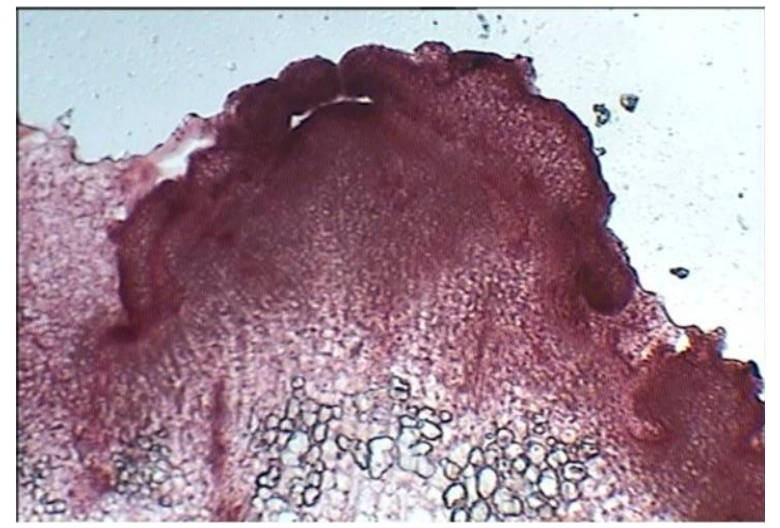

Fig. 4 Section of the embryo originated from cotyledon after 8 days of culture
NAA had a higher potential with respect to the induction of roots in this cultivar than IBA (Fig. 3). Shoots rooted properly after 4 weeks of subculturing. Regenerated plantlets were used repeatedly as new materials for the next cycles of regeneration (Fig. 3).

The proliferated plants showed 90-95\% survival during hardening and acclimatization (Fig. 5).

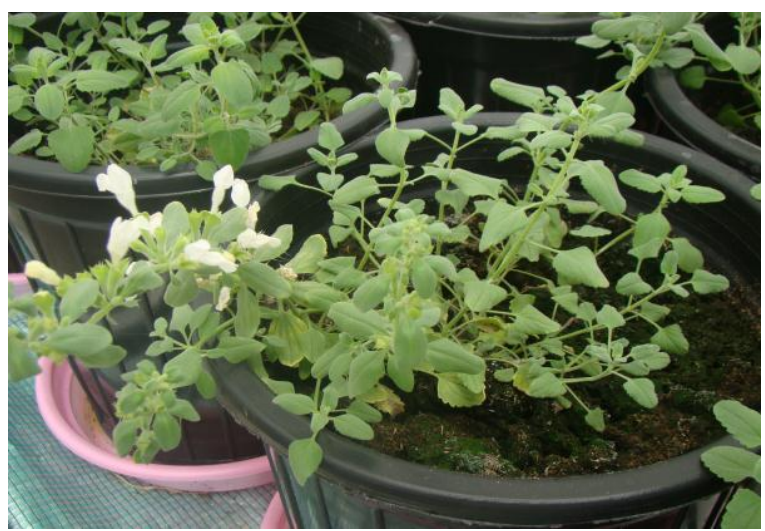

Fig. 5 Hardened plantlet of Dracocephalum kotschyi Boiss. in a phytotron after transferring from in vitro conditions

There were no observable variations between the parent plants and in vitro propagated plants. The transplanted plantlets established well in a glasshouse (Fig. 6).

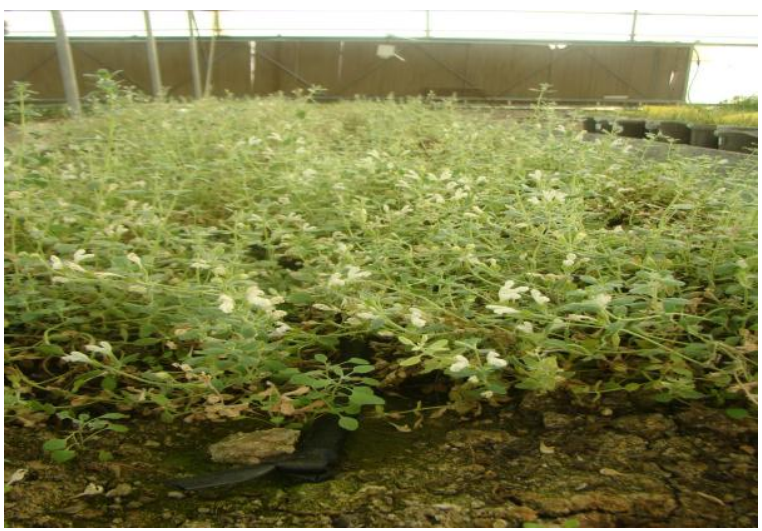

Fig. 6 Dracocephalum kotschyi Boiss. whole plants planted in a greenhouse

\section{DISCUSSION}

The literature on regeneration of Dracocephalum kotschyi and the role of plant growth regulators don't reported yet, but there is different reported regeneration of the family Lamiaceae. These studies used different species, varieties and explants and a vast range of in vitro regeneration media and/or strategies. The regeneration of that family from nodal segments has been considered as a relative simple method, which could be potentially applied for mass propagation of the species (Dode et al., 2003; Irina et al., 2004; Naghibi et al., 2005; Lucia, SA et al., 1994; Luis, JG et al., 1992; Mederos, 1991; Mederos, et al., 1997).

The importance of BAP for regeneration of different plants of Lamiaceae family, for example Ocimum spp., has been emphasized by Dode et al. (2003), Nirmal and Sehgal, (1999) and David and Arockiasamy(2008), who showed that MS medium supplemented with $5 \mathrm{mg} / \mathrm{L}$ BAP plus $0.5 \mathrm{mg} / \mathrm{L}$ 
NAA was effective for shoot multiplication in nodal explants of Ocimum basilicum L. Kiran Ghanti et al. (2004) showed that MS medium supplemented with $1 \mathrm{mg} / \mathrm{L}$ BAP was effective for shoot multiplication in nodal segment of Mentha piperita L. In our study, the concentration of BAP lesser than $2 \mathrm{mg} / \mathrm{L}$ was less effective for regeneration of D. kotschyi. Another cytokinin, KIN, alone or in combination with auxins was not effective for the regeneration of $\mathrm{D}$. kotschyi. The minimum number of shoots was regenerated in media containing KIN in combination with IBA or NAA. This was in accordance with previously report (David and Arockiasamy, 2008).

In our experiment NAA was more effective than IBA with respect to rooting of the regenerated shoots. The shoot buds proliferating from axillary shoot nodal explants rooted easily in medium supplemented with NAA. The axillary shoots further produced multiple shoot buds when cultured in bud induction medium. The in vitro established plantlets were hardened in a phytotron with a survival rate of $90-95 \%$ and were then transplanted in glasshouse (David and Arockiasamy, 2008).

Overall findings of the present study are significant in obtaining the maximum regeneration with minimum concentrations of growth regulator.

\section{CONCLUSION}

Lamiaceae family is well represented in traditional and folk medicine D. kotschyi, is rich in aromatic essential oils and valuable for its pharmaceutical, aromatic and culinary properties. The present study showed the procedure for micropropagation of D. kotschyi using nodal segments from in vitro germinated plants. We have developed a promising method for an efficient regeneration from nodal explants of Dracocephalum kotschyi Boiss. Using BAP and NAA, our experiment indicated the explants include shoots bud of different process of their development. As seen in following days of culturing only parenchyma cells were observed, whereas apical meristem in maturity situation was seen and the completed meristem with prymordia leaves was seeing after 12 days. The protocol could be useful for large scale production of single genotypes and provides a possible system towards genetic improvement of the crop.

\section{REFERENCES}

[1] Amirghofran, Z, Azadbakht, M, Karimi, MH. Evaluation of the immunomodulatory effects of five herbal plants. J. Ethnopharmacol. 72:167-72. 2000.

[2] Begum, FM, Amin, N, Azad, MAK. In vitro Rapid Clonal Propagation of Ocimum basilicum L. Plant. Tissue. Cult. 12:27-35. 2002.

[3] Cordell, GA., Beecher, CWW, Pezzuuto, JM. Can ethnopharmacology contributesto the development of new anticancer drugs. J. Ethnopharmacol. 32:117-133. 1991.

[4] Cox, PA., Balick, MJ. The ethnobotanical approach to drug discovery. Sci. Am. 270:82-87. 1994.
[5] David Raja, H, Arockiasamy, DI. In vitro Propagation of Mentha viridis L. from Nodal and Shoot tip Explants. Plant. Tissue. Cult. Biotech. 18:1-6. 2008.

[6] Golshani S, Karamkhani F, Monsef-Esfehani HR, Abdollahi M. Antinociceptive effects of the essential oil of Dracocephalum kotschyi in the mouse writhing test. J Pharm Pharmaceut Sci. 7:76-79. 2004.

[7] Irina, T, Constantin, T, Gogu, G. Histo-anatomy and in vitro morphogenesis in Hyssopus officinalis L. (Lamiaceae) Acta. Bot. Croat. 63: 59-68. 2004

[8] Jahaniani, F, Ebrahimi, SA, Rahbar-Roshandel, N, Mahmoudian, M. Xanthomicrol is the main cytotoxic component of Dracocephalum kotschyii and a potential anticancer agent. Phytochemistry. 66: 1581-1592. 2005.

[9] Kiran, GCP, Kaviraj, RB, Venugopal, FTZ, Rao, S. Rapid regeneration of Mentha piperita L.from shoots tip and nodal explants. Indian J. Biotech. 3:594-598. 2004.

[10] Dode, LB, Seixas, FK, Schuch, MW, Braga, EJB, Bobrowski, VL. In vitro clonal propagation of Ocimum basilicum $\mathrm{L}$. (Lamiaceae). Acta Scientiarum, Maringá. 25: 439-441. 2003.

[11] Lucia, S A, Javier, G L, Sebastiana, M, Molina, A, G and Isabel, L B. Estudio fitoquimico de la parte aerea de Salvia canariensis L.cultivada in vitro. Proc. das II Jomadas de Plantas Medicinais, Aromaticas e Oleos Essenciais, LNETI (Ed.), Queluz, Lisboa, Portugal (Span).1: 111-115. 1994.

[12] Luis, JG, González, AG, Andrés, LS and Mederos, M S. Diterpenes from in vitro-grown Salvia canariensis L. Phytochemistry 31: 3272-3275. 1992.

[13] Mederos, S. In vitro propagation of Salvia canariensis L. In Vitro Cell. Dev. Biol. Plant, 273: 385. 1991.

[14] Mederos, M S, Andres, LS, Luis, J and Gonzalez, A. Studies on the isolation of diterpenes from in vitro propagation of Salvia canariensis L. Plant Tiss. Cult. 701:29-34. 1997.

[15] Murashige, T, Skoog, FA. Revised medium for rapid growth and bioassays with tobacco tissue cultures. Physiol. Plant. 15: 473-497. 1962.

[16] Naghibi, F, Mosaddegh, M, Mohammadi, MS, Ghorbani, A. Labiatae Family in folk Medicine in Iran: from Ethnobotany to Pharmacology. Iranian J. Pharm.Res. 2: 63-79. 2005.

[17] Nirmal, KS, Sehgal, CB. Micropropagation of 'Holy Basil' (Ocimum sanctum Linn.) from young inflorescences of mature plants.Plant Growth Regulation. 1. 2010.

[18] Sahoo, Y, Pattnaik, SK, Chand, PK. In vitro clonal propagation of an aromatic medicinal herb Ocimum basilicum L. (sweet basil) by axillary shoots proliferation. In Vitro Cell. Devel. Biol. Plant, Largo. 33:293-296. 1997.

[19] Sajjadi, E, Movahedian, S, Yektaian, A. Antihyperlipidemic effect of hydroalcoholic extract, and polyphenolic fraction from Dracocephalum kotschyi Boiss. Pharm. Acta. Helv. 73:167-70. 1998.

[20] Sobhani, AM, Ebrahimi, SA, Mahmoudian, M. An in vitro evaluation of human DNA topoisomerase I inhibition by Peganum harmala L. seeds extract and its beta-carboline alkaloids. J. Pharm.Pharm. Sci. 5: 19-23. 2002.

[21] Winthrop, BP, Simon, JE. Shoot regeneration of young leaf explants from basil (Ocimum basilicum L.), In Vitro Cell. Dev.Biol. Plant, Largo. 36: 250-254. 2000.

[22] Wu, J, Wu, Y, Yang, BB. Anticancer activity of Hemsleya amabilis extract. Life Sci. 71: 2161-2170. 2002. 